\title{
Das Notizbuch eines Tiroler Notars aus dem 14. Jahrhundert. Von
}

F. Schillmann.

Bei einer Arbeit über mittelalterliche Formel- und Briefbücher fand ich im Statthaltereiarchir zu Innsbruck den im Nachfolgenden behandelten kleinen cod. 120, der wegen seives mannigfaltigen Inhalts einiges Interesse beansprucht ${ }^{1}$ ). Es ist ein kleines Heftchen von 20 Blättern Papier in Format 20, $5 \times 14, \overline{\mathrm{c}} \mathrm{cm}$, nicht gebundeu. Diese Blätter sind in zwei Lagen geheftet, die erste umfasst Bl. 1-12, die $\mathrm{zweite,}$, in der einige Seiten fehlen, Bl. 13-19, mit Bl. 20 begann eine neue Lage, von der aber die folgenden Seiten kaum beschrieben waren und jetzt abgetrennt sind. Von Bl. 20 ist die untere Hälfte, die wohl keinen Text mehr trug, abgeschnitten, ausserdem sind Bl. $17^{r}$ und $19^{r}$ unbeschrieben. Die Paginierung ist modern. Äusserlich wird die Herkunft des Bändchens durch nichts bezeichnet, auf der Rückseite von Bl. 20 steht von einer Hand saec. 16. ineunt. ,Instrument formülar ${ }^{2}$ ). Das Wasserzeichen ist ein Schwertknauf.

1) Der Direztion des k. k. Statthaltereiarchivs, die wir den cod. nach meiner kurzen Einsicht in Innsbruck, zu weiterer Bearbeitung gütigst an das Kgl. Staatsarchiv in Marburg eandte und meine verschiedenen Anfragen in liebens. würdigster Weise beantwortete, fühle ich mich zu grossem Dank verptlichtet. Ferner möchte ich Herrn Stiftskapitular L. Wiedemayr in Innichen auch an dieser Stelle für seine gütigen Mitteilungen über die Personalien der Innicher Chorherrn meinen verbindlichsten Dank aussprechen, sowie auch Herrn Professor W. Meyer in Göttingen für seine freundliche Durchsicht der Rätsel.

2) Wegen des mannigfaltigen Inhalts sehe ich hier von der Bezeichnung Formelbuch $a b$ und nenne den cod. lieber Notizbuch. 
Der Inhalt in kurzer Ũbersicht zusammengestellt ist folgeuder:

Bl. 1r. Eine medizinische Regel. - Entwurf zu einer Briefadresse. - Federproben. - Ein Hexameter mit Neumen.

Bl. 1. Regula dictaminis in Versen. - Lateinische Rätsel. Eutwürfe zu einem Notariatssignet.

Bl. $2^{r}-9^{r}$. Briefe und Urkunden.

Bl. $9^{v}-12^{v}$. Ein philosophischer Traktat: Regimine moderuorum (unvollständig).

Bl. 13r. Chronologische Regel. - Mittelhochdeutsche Verse.

Bl. $13^{r}-14^{\text {r }}$. Zwei Sequenzen mit Neumen.

Bl. $14^{\vee}-16^{v}, \mathrm{Bl} .17^{\vee}-18^{\mathrm{r}}$. Briefe und Urkunden.

Bl. 18 ${ }^{\nabla}$. Anleitung zur Abfassung einer Orkunde.

Bl. $19^{r}-20^{r}$. Urkunden. - Notariatssignet.

Mit Ausnahme des ersten Blattes ist die ganze erste Lage von ei in e m Schreiber, allerdings mit Tinten- und Federwechsel, geschrieben, doch auch Bl. 1 rübrt, mit Ausnahme der regula dictaminis und einiger Federproben von seiner Hand her. Dagegen weist die zweite Lage drei verschiedene, weun auch alle gleichzeitige, Hände auf und zwar stammen je von einem Schreiber Bl. $13^{r}-14^{r}, B l .14^{v}-18^{v}$, Bl. $19^{r}-20$.

Wie schon gesagt, wird die Herkunft der Handschrift äusserlich durch nichts dokumentiert. Doch liess sich aus den Akten des Statthaltereiarchivs feststellen, dass sie sich bereits im alten landesfürstlichen Schatzarchiv (Lade 43) befand, in dem auch der Dorsualvermerk ,Instrument formülar" geschrieben wurde. Nach dem alten Repertorium der Görzer Registratur (pag. 1782) stammt das Heft aus dem Archiv der Grafen von Görz in Lienz, das nach deren Aussterben im Jahre 1500 mit dem Innsbrucker Hausarchiv vereinigt wurde ${ }^{1}$ ). Wie aber kam es in die Görzische Kanzlei? Eine Beantwortung dieser Frage kann nur aus dem Inhalte erfolgen, und sie lässt sich mit einiger Wahrseheinlichkeit geben. Auf Bl. 1 und Bl. 20 finden sich Notariatssignete in der üblichen Form, mit einem F im Quadrat. Der Zeichner desselben ist sicher mit einem der Schreiber des Heftes identisch. Der Versuch nach dem Signet den Verfasser unseres Kodex zu bestimmen, misslang, da die Ausfertigung förmlicher mit dem signum notarii versehener Notariatsinstrumente in d e m Teile Tirols, in dem das Heftchen sicher entstanden, im Pustertal, durchaus nicht äblich war. Das F des Signets weist nun auf den Namen Fridericus hin. Ein Fridericus secundus socius s. Margarete (in Krain) hat nun 1314 Mai 14 das bis-

1) Diese Nachrichten verdanke ich einer gütigen Mitteilung des Statthaltereiarchivs.

Mittoilungen XXXI. 
her im Stiftsurchiv za Innichen auf bewahrte Testament des Bischofs Gerold von Emona teilweise in den Formen eines Notariatsinstrumentes geschrieben ${ }^{1}$. Nnn enthält unser Kodex ron demselben Tage. dem Todestage Gerolds, eine Bestätigung des Testaments durch den Archidiakon in Krain und der Mark (nr. 7), die sicherlich derselbe Friedrich schrieb2), Wir haben hier also den ersten Anhaltspunkt. Zu den von Gerold in diesem Testament Bedachten gehört der Laie Nicolaus von Innichen, vermutlich ein Verwandter, vielleicht Bruder, des in nr. 36 u. 38 genannten Laien Konrad von Innichen, von dessen Söhnen der eine, Friedrich, Scholar in Wien war. Ferner haben wir in nr. 14 die Bitte des Grafen Albert von Görz und Tirol an Bischof Albert von Brixen, seinem Notar, dem Scholar F., ein beneficium ecclesiasticum zu verleihen.

Hieraus glaube ich folgendes schliessen zu dürfen: Der Verfasser des Heftchens ist Friedrich, ein Sohn Konrads von Inuichen, der zunächst Scholar in Wien war, nach Abschluss seiner Studieu in seine Heimat zurückkehrte und wahrscheinlich dem Stift Innichen angehört hat, er wurde Hilfsgeistlicher in Weisskirchen und später Notar des Grafen Albert von Görz und Tirol, was nicht weiter wunderbar ist, da diese Grafen die Schirnvogtei über Innichen besassen ${ }^{3}$ ).

Nehmen wir diesen Lebeuslauf des Verfassers an, so könuen wir die Zusammenstellung des Heftchens leicht erklăren. Denn neben einigen wenigen Privatbriefen haben wir Urkunden des Stiftes Innichen und der Grafen ron Görz. Wir brauchen also nicht weiter zu untersuchen, wie der Verfasser in den Besitz der Urkunden kam $^{4}$ ), auch ist damit gleichzeitig die Herkunft aus der Görzer Kanzlei erklärt. Schivierigkeiten bietet nur noch die Abfassung durch verschiedene Schreiber. Ist auch eine endgültige Lösung der Frage nicht möglich, so kann mau doch wohl vermuten, dass der Notar Friedrich, als er Ergänzungen zu dem ersten vou ihm geschriebenen Teile machen wollte, diese von seinen Unterschreibern eintragen liess.

1) Archivberichte aus Tirol $3 \mathrm{nr} .2574$ (leider liess sich zur Zeit diese Ur. kunde nicht auffinden).

2) Das Or. dieser Bestätigung ist nicht mehr erhalten.

3) Der Versuch einer Schriftrergleichung dieses Heftchens mit Urkunden des Stiftsarchivs in Innichen fübrte zu keinen Resultat. Ebenso blieb eice Diktatuntersuchung der hier gegebenen Stücke ohne Erfolg. Auffällig ist. dass der Bischof Alkert ron Brixen in diesen Lrkunden stets ganz unkanonisch mit seinem Zunamen de Enna genannt wird, was in anderen von ihm erhaltenen Lrkunden nicht der Fall ist.

4) Nur die Herkunft der beiden Augsburger Urkunden nr. 39 und 31 blicb mir unklar. 
Die ganze Sammlnng hat durchaus privaten Charakter, der Verfasser wollte sich wahrscheinlich nur alles, was ihn interessierte, in einem Hefte zusammenstellen, irgendwelche didaktischen Zwecke wird er kaum dabei im Auge gehabt haben. Wollte man wirklich annebmen, er habe ein Formelbuch für die Görzer Kanzlei anlegen wollen, woranf vielleicht die Oberschriften bei den ersten Stücken hinweisen könnten 1 ), so wäre die Anlage und Answahl der einzelnen Schreiben sehr unpraktisch. Die Abfussungszeit der Sammlung ergibt sich aus den datierten Stücken und den vorkommenden Namen, sie wäre etwa 1340 auzusetzen.

Die Urkunden und Briefe, die sämtlich nicht mehr im Original oder in anderen Abschriften erhalten sind, bieten einen Blick in die inneren Verhältnisse des Pustertals und benachbarter Gebiete im 14. Jahrhundert, während die übrigen Beigaben kultur- und literargeschichtliches Interesse beanspruchen können.

Die Texte sind meist überaus flüchtig und fehlerhaft geschrieben, so dass es oft schwer war, das Richtige za treffen. Auch verwenden die Schreiber des Kodex z. T. ganz eigentümliche Abbreviaturen, deren Auflösung trotz der freundlichen Unterstützung der Herren des Marburger Staatsarchirs, denen ich an dieser Stelle meinen herzlichsten Dank dafür aussprechen möchte, doch vielfachen Schwierigkeiten begegnete.

Der folgende Abdrack bietet zunächst die Urkunden, die zeitlich genauer bestimmt werden konnten, in chronologischer Reihenfolge, dann die undatierten Stücke und im zweiten Teil die übrigen Notizen ${ }^{2}$ ). Briefe und Urkunden, die nur ganz lokales Interesse beanspruehen, werden im Regest gegeben. Nicht aufgenommen wurde der verhältnismässig umfangreiche Traktat, einerseits weil er nur Fragment ist, vor allem aber weil zu seinem Verständuis ein tieferes Eindringen in die mittelalterliche Philosophie nötig gewesen wäre, wozu es dem Herausgeber sowohl an Zeit wie an Neigung fehlte. Seine Veröffentlichung sei einem Berufeneren vorbehalten ${ }^{3}$ ).

1) Soweit solche vorkommen, sind sie mit blauer Tinte geschrieben.

2) Es mag hier angemerkt werden, dass auf fol. 2 vor dem Beginn der Briefe und Urkunden der gebräucbliche Wunsch steht: Assit principio sancta Maria meo. Vgl. Wattenbach, Schriftwesen (3. A.) S. 49?.

s) Im folgenden sind mit Abkürzungen angeführt: Archivberichte aus Tirol von Ottenthal und Redlich Bd. 3 (cit. OR und nr.); J. Zahn, Cod. diplom. Austriaco-Frisingensis 3 Bde., (die beiden ersten nach den Nummern, Bd. 3 nach der Seitenzahl); Acta Tirolensia Bd. I.; die Nekrologe nach der Ausgabe der Monum. German. histor. Necrologia Bd. 3 ; Sinnacher, Beitrăge zur Geschichte der 
1.

Bischof Landolf von Brixen bittet die Gräfin Eufemia von Görz, ihn und die Kivche zu Brixen vor den Bedrohungen des Heinrich Fulin zu schützen, mit dem er erst kurz vorher einen Friedensvertrag geschlossen ( $\left.f . \tau^{\nabla}\right)$.

$$
\text { [1300 Oktober \&-1301 März 26]. }
$$

Inclite domine et preclare, domine Eufomie nobili comitisse Goricie ${ }^{1}$ ) Landolfus dei gracia episcopus Brixinensis2) cam obsequiorum promtitudine oraciones in virginis filio gloriose. Vestre pateat excellencie per presentes, quod Brunekkam renimus, ibidem reditnm spectabilis comitis Al(berti) mariti vestri, cuins consiliis super quibusdam arduis ecclesie nostre negociis uti volamus et regia), exspectare volentes, scilicet inter nos et Hainricum Fulinum facta concordia faerit ${ }^{3}$ ) et per ipsum et quosdaw suos iuratum fuerit, quod ipsa concordia perpetno debeat inviolabiliter observari et neque nos nec ecclesia nostra debeamus ab eodem $\mathrm{H}$. vel suis de cetero quoquomodo molestari, super hoc quoque fideiussoriamb) receperimus caucionem pro quingentis marcis, idem tamen Fulinus omnium predictorum penitus inmemor die lune proxime transacto per nobilem virum Hngonem de Taufers multis probis viris et honestis presentibus comminaciones inferens nobis multas, n03 et omnja bona nostra et ecclesie Brixinensis temere diffidavitc), mortem nobis magnis iuramentis comminando. Quapropter dicti Fulini presumptuosam violenciam intimamus benevolencie conquerendo, suplicantes humiliter et instanter, quatenus, cum sitis ecclesie nostre advocatrix benignissima et tutrix potentissima, propter dei misericordiam et sanctorum patronorum ecclesie nostre reverenciam nos et ecclesiam nostram a dicti Fulini violentis iniuriis et iniuriosis oppressionibus dignemini defendere vel defenssare, recipientes nos et nostra in vestram tuicionem, conductum et graciam specialem super boc nobis per latorem presencium vestre benevolencie transmittentes ${ }^{d}$ ) litteras graciosas, quod aput vestre pietatis eminenciam libentissime volumus promereri. Datum.

a) Davor et honoris gestr. - b) cod. fedefissoriam. - c) cod. duffidavit. d) cod. transmittente.

Kirchen Säben und Brixen (Brixen 1821;34) Bd. 4 und 5; Resch. Aetas millenaria ecclesie... Inticensis (1772), hieraus kaw für diese Arbeit nur das Verzeichnis der Pröpste in Betrasht. Die neuste Arbeit über Innichen ist L. Wiedemnyr, Die Hofmark Innichen Bd. 1, (Innichen 1908) sie ist durchaus populär gehalten und beruht auf den Arteiten von Resch und Sinnacher.

1) 2 weite Gerahlin des Grafen Albrecht I. ron Görz (1267-1304).

2) Bischof Landolf 1295-1300 oder 1301 .

s) Ein Streit mit Heinrich Fulin, der zu Aufhofen bei Bruneck widerrechtlich einen Turm gebaut und der Kirche von Brixen vielen Schaden getan, war am 4. Okt. 1300 durch den hier angedeuteten Vergleich scheinbar geschlich tet worden ( $\mathrm{vgl}$. Sinnacher $j, 50 \mathrm{ff}$.). Bald nachber muss obiges Schreiben fallen, welches zeigt, dass Fulin keine Rube hielt. Sollte vielleicht das gewaltsame Ende Bischof Landolfs (vor 26. März 1301) danit zusammenhängen? 
2.

Das Kapitel zu Brixen bittet die Gräfin Eufemia von Görz und Tirol und ihren Sohn Albert, den Plancho von Entholz gegen die Übergriffe Wilhelms, des Bruders Ottos von Anras, zu schützen ( $f .8)$.

Brixen [1301] Juli 31.

Excellenti domine sue, domine Eufomie nobili comittisse, necnon domino Al(berto) eius filio, illustri comiti Tyrolis et Goricie ${ }^{1}$ ), Fridericns decanus $^{2}$ ) totumque capitulum ecclesie Brixinensis salutem cum omnibus devotis, paratam ad quelibet obsequia voluntatem. Conquestus est nobis Plancho de Entholz ecclesie nostre filius, vester servitor specialis, quod Bilhaimus frater Ottonis de Anras sili predium quoddam dictum Vischlehen ${ }^{3}$ ), quod nomine ecclesie nostre multis annis possedit pacifice et quiete, ocupat et ocupare intendit sine causa qualibet violenter. Quapropter dominacioni vestre sopplicamus obnexius multama) ac devote, quatenus eidem propter deum necnon precum nostrarum intuitu detis in mandatis firmiter, $u^{b}$ ) usque in creacionem futuri episcopi a tali violencia resipiscat. Paratus est enim dictus Plancho in eiusdem episcopi aut capituli nostri presencia sibi super hiis, pro quibus ipsum impetere duserit, exhibere amoris vel iusticiec) complementum. Datum Brisine in die sancti Tertulini martiris.

3.

Der General des Predigerordens Aymericus macht den Vicepleban Gerold von St. Lorenzen der Gebete und guten Werke des Ordens teilhaftig (f. 7\%).

Padua [1308].

Provido et honesto viro ac in Christo devoto domino Geroldo viceplebano de sancto Laurencio ${ }^{4}$ ) frater Aymericns $^{d}$ ) fratrum ordinis Predicatorum magister ${ }^{5}$ ) salutem et incrementa continua gracie ${ }^{\theta}$ ) salutaris. Vestre devocionis affectus, quem ad nostrum habetis ordinem, specialem esigenciam dignef) requirit, ut de beneficiis divine clemencie ordini nostro concessis specialis vobis participacio concedatur. Propter quod vobis omnium missarum, oracionum, predicacionum, ieiuniorum, vigiliarum, laborum ceterorumque bonorum, que per fratres ordinis 8 ) nostri dominus per mun-

a) Übergeschrieben. - b) cod. ac. - c) cod. iusticia. - d) cod. Americus. - e) cod. gracia. - i) cod. digna. - g) corr. aus ordine.

1) Albrecht II. bis 1326 .

2) Friedrich wird 1291-1302 als Dekan erwăhnt vgl. Acta Tirolen. I. 662, $664,671,672,673 \mathrm{a}, 691,694$. Die Urkunde fällt in die Zeit der Sedisvakanz nach der Ermordung Bischof Landolfs.

3) Auch Vischelein, Vischeleyne b. Innichen.

๑) S. Lorenzen b. Bruneck.

5) Aymericus Placentinus magister generalis 1304-13i1 (resign.) † 1327 Angust 12 ( 
dum fieri $i^{a}$ ) dederit universum, participacionem concedo tenore fresencium specialem, $\mathbf{a t b}^{\mathrm{b}}$ ) in vita pariter et in morte et maltiplici suffragiorum presidio et hic a malis protegi et in futaro mereamini in eterna tabernacula feliciter introdaci. In cuins concessionis testimoninm sigillum nostram duxi presentibus aponendum. Datum Padue ${ }^{1}$ ) in nostro capitulo generali.

4.

Ottobonus Patriarch ron Aquileia teilt dem Kapitel von Innichen mit, dass Bischof Emicho von Freising das Patronat und Kanonikat der Michaeliskirche bei Innichen, das Gerold als Dekan von Innichen innegehabt, diesem auch als Bischof ron Emona überlassen habe $\left(f .8^{\nabla}\right)$.

Cucagna [1308-1311].

Ottobonus dei gratia sancte sedis Aquilegensis patriarcha ${ }^{2}$ ) viris venerabilibus et discretis universitati capituli Inticensis salutem cum sincero caritatis affectn. Cum ecclesia Emonensis, ad quam $G$ (eroldus) decanus ${ }^{3}$ ) ecclesie vestre dei et nostra gracia est promotus, adeo sit exilis, quod ipsius redditus non sufficiant immo nec competant ut statui et ordini presulatus, et propter ipsius exhiguitatem venerabilis in Christo pater dominus Emichoc) episcopns Frisingensis ${ }^{4}$ ) de benignitate canonica et de iuris mansuetudine sibi indalserit et expresse concesserit, ut ecclesiam barrochialem sancte Michahelis apud Inticam, quam obtinet, in qua ias habere dignoscitur patronatus, et canonicatum, quem ibidem optinet in quantum ibidem dignoscitur dominus fundi esse, retineat pro tempore vite sue non obstante provisione sua ad predictam ecclesiam Emonensem, universitatem vestram affectuosius deprecamur nichilominus exhortantes, quatenus ipsam velitis non obstante predicta provisione sua de benignitate canonica et iuris paciencia in vestro consorcio affectu benivolo retinere, cum ipsum alias eciam ex gratuitu, immo si a vobis vellet discedere, non dimittere pocius deberitis et valde difficile sit et grave, sicut vestra consideracio satis novit, venerabilis patris dọmini episcopi Frisingensis ac domini $\mathrm{H}$ (einrici) comitis Goricie ${ }^{5}$ ) adrocati vestri voluntatibus difficultatem inducere ac eorum precibus non parere maxime in hiis, que paciencia iuris suadet. Datum in obsidione castri Kukanie ${ }^{6}$ ) septimo intrante ${ }^{d}$.

a) Čbergeschrieben. - b) fehlt cod. - c) cod. Emcho. - d) Darauf folgt als Beginn einer neuen Urkunde: Viro egreio et potenti domino Albubino capitaneo Veronensi ac eius tratri consules...., vgl. n. 30.

1) Das Generalkapitel in Padua tagte 1308 (Monum. ord. Predicator. V. 194).

2) Ottobonus Fatriarch von Aquileia 1302-1315.

3) Gerold ron Tessenberg, erst Chorherr und Pfarrer, dann 1301-1308

Dekan ron Innichen, Bischof von Emona 1308-1314 (vgl. Sinnacher 3, 477).

4) Emicho Bischof von Freising 1283-1311.

3) Heinrich II. 1304-1323.

6) Cucagna in Friaul. 
5.

Bertold gen. Phaff (Perchtoldus dictus Phaffe) von Wisen ${ }^{1}$ ) kauft von Ulrich dem Sohn des Jakob Lirator und dessen Frau Christine ein Haus einschliesslich des Platzes in Niederdorf ${ }^{2}$ ) am Bache Aschurra (cis rippam, que Aschurra vulgariter dicitur) nebst zwei anliegenden Gärten für 40 librae Veronensium, unter Vorbehalt des Rückkaufrechtes des Ulrich innerhalb der nächsten drei Jahre gegen Rückzahlung der Kaufsumme unter Zurechnung eines Denars. Unter dem Siegel des Ulrich von Taisten, Richters von Welsberg ${ }^{3}$ ). Zeugen: Christianus dictus Chalbo de Taisten), N'ycolaus filius Perchtoldi Phaff, Hainricus de Pudie ${ }^{5}$ ) et Heinricus affinis Perchtoldi de Wisen. Acta sunt hec in Taisten in domo Christiani a. $d_{\text {. }}$ V. $\mathrm{CCC}^{\circ} \mathrm{VIIII} \mathrm{I}^{\circ}$, tercio intrante decembri ( $\left.f .2\right)$.

Taisten 1309 Dezember 3.

6.

Albert, Propst des Klosters Neustift, bittet den Bischof Gerold von Emona, mit aller Schärfe gegen Bonellus und Petrus, die das Stift dauernd belästigen, vorzugehen ( $\left.f .8^{\mathrm{v}}\right)$.

[Vor 1314 Mai].

Reverendo in Christo patri et sibi specialiter dilecto domino et amico, domino Geroldo venerabili episcopo Emonensi, Al(bertus) divina miseracione prepositus Novecelle ${ }^{6}$ ) quidquid valet reverencie, obsequii et honoris cum oracionibus derotis. Petimus ex affectu et quam intime supplicamus, quatenus sicat ceperitis contra Bonellam et Pelrum nepotem suum necnon contra clericos in hac parte nobis ${ }^{a}$ ) inobedientes et nos ${ }^{b}$ ) iniaste contempnentes, quantum potestis de rigore iuris procedatis; quod hoc vobise) videtar licet non subito, tamen in futurum optime profaturam. De composicione inter nos et $\left.\operatorname{es}^{\mathrm{d}}\right)$, sicut nobis scripsistis et quam consuluistis ${ }^{\natural}$, sciatis, quod concordare non potuimas, quia nimia dampna nobis et nostris hominibus hactenus intulerunt nec inferre desistunt, et si aliquid iuris vel gracie eis in

a) cod robis. - b) cod. ros. - c) cod. nobis. - d) cod. ros. - e) cod. quas consiluiatis.

1) Wiesen Bez. Welsberg.

2) Bez. Welsberg.

3) Ulrich wird als Richter von Welsberg erwähnt 1334 (OR 2039), 1337 (eb. 2645), 1341 (eb. 2053).

4) Christian der Chalp ron 'laisten wird 1333 genannt (OR. 2312), im lib. anniversariorum des Kl. Nenstift ist er unter dem 18. Juni verzeichnet.

s) Wird 1317 als Lehnsmann ron Freising genannt (Zahn III, 122), auch 1347 (OR. 1190).

6) Im Nelrolog des Kl. Neustift ist 1318 April 12 als sein Todestag angegeben. 
dictis nostris ${ }^{a}$ hominibus et possessionibus permittemus, maledictionem incedere perpetuam pertimemus $s^{b}$ ) necnon damna, que in futurum recuperare nullatenus possemus.

7.

Tyberius de la Ture, Archidiakon von Krain und der Mark, Ifarrer in Weisskirchen, bestätigt das Testament des Bischofs Gerold ron Emona1) $\left(f .8^{\vee}\right)$.

Weisskirchen 1314 Mai 14.

Ego Tyberius de la Ture, archidiaconus Carnioie et Marchie necnon plebanus Albe ecclesie in Marchia dicta, profiteor in hiis scriptis, quoniam presencialiter interfui, ubi dominus Geroldus venerabilis episcopus Emonensis $^{2}$ ) pater, corpore quidem debilis mente vero sanusc), voce propria sua delegavit testamenta multis coram honestis presbiteris $^{d}$ ), vicariis et sociis vicariorum plurimisque hominibus fidedignise) in domo mea aput ecclesiam sancte Margarete proxima ${ }^{f}$ ) tercia feria ante festum ascensionis sub anno domini $\mathrm{MI}^{\circ} \mathrm{CCC}^{\circ} \mathrm{XIIII}$; statimque dicta sua testamenta conscribi iussi. Qui die eodem mei in presencia spiritum proch dolor tradidit. Quem in prefata mea ecclesia sancte Margarete presentibus nobilibus de Reutenberch ${ }^{3}$ ) cum multis sacerdotibus, scolaribus et populo, prout honestius valui, sepelivi. Qui inter cetera sua testamenta suis legavit familiaribus Nycolao de Intichingen layco, Nycolao scolari eiusdem loci, Chunzlino de Carintia de loco qui dicitur Reifniz ${ }^{4}$ cuilibet ipsorum pro suisg) serviciis et laboribus equam, in quo quisque ipsorums) secum veniebat, et at non de hoc in locis remocioribus ambiguitas aliqua de ipsis habeatur, presentes duxi sigillo meo unacum sigillo predictorum dominorum de Reutenberch ${ }^{\mathrm{h}}$ ) consignari.

8.

Siıpplik der Gräfin Eufemia ron von Görz, an Papst Johann XXII., dem Domherrn Bartholomeus de Vallesella von Trient ein Benefizium zu verleihen (f. 18).

[Nach 1316].

Sanctissimo in Christo patri et domino suo domino Johanni digna dei providencia sacrosancte Romane ac universalis ecclesie dignissimo summo

a) Übergeschrieben - b) cod. pertimus - c) cod. sanos - d) cod. prespiteris -- e) cod. fidedigna - 1) davor presentibus nobilibus gestr. - z) über. geschr. - h) cod. Reifenbercb.

i) Das Testament seibst von 1310 Januar 24, eine Wiederhoiung anf dem Totenbette OR. 2569, 2574 (rgl. Einl.).

2) Gams nennt ihn Gïraldus und tälschlich als zum Predigerorden gehörend. Eubel konnte ihn selbst nicht nachweisen und druckt die Notiz ron Gams ab. Sein Todesjahr kennen beide nicht.

9) Keutenburg b. Nassenfuss in Kärnten.

4) Unweit Klagenfurt. 
pontifici devota eius filia Enfmya de Polonia dei gracia ducissa Karintie, Tyrolis et Goricie comitissa cum humilissima recommendacione se ipsam ad pedum oscula beatorum. Sanctitati vestre, que suis fidelibus inste petentibas semper consuevit sue ianaam gracie aperire, instancia quanta possum supplico humiliter ac devote, sperans restram graciam vel clemenciam tante largitatis munere affluentem, quod quidquid vobis duxero supplicandum non dubito veraciter obtinere, quatenus carissimo meo domino Bartholomeo de Vallesella canonico ecclesie Tridentine, sancte Romane ecclesie fidelissimo et devoto, digne ${ }^{\mathrm{s}}$ ) eius exigentibus meritis promovendo, pro quo alias clemencie restre supplicavi humiliter et tamen a vobis nullam graciam reportavit, quod magis ex oblivione quam ingratitudine non dubito contigisse, de aliquo beneficio vacante vel vacaturo meis precibus et amore providere dignetur vestra sanctitas graciosa. Quod si clemencia restra adimpleverit, sicat spero, mihi prelibatam graciam attribuam fore factam. Altissimus vos conservet per tempora longiora libere dominantes ecclesie sancte dei.

9.

Bischof Johann von Brixen fordert den Balduin, Vikar der Pfarrkirche zu Innichen, auf, den Chorherrn Gerold d. J. vor ihn zu zitieven, damit er sich gegen die Klagen des Kapitels von Innichen verantuiorte (f. 4).

Brixen [vor 1321].

Johannes miseracione divina Brixinensis episcopus ${ }^{1}$ ) discreto viro Paldwino vicario parrochialis ecclesie in Intica salutem in domino. Volumus et mandamus tibi in virtute sancte obediencie et sub pena excommunicacionis, quatenus Geroldum iuniorem canonicum [ecclesie] ${ }^{b}$ ) Inticensis predicte ad nostram seites presenciam, ut feria tercia proxima post dominicam Quasimodogeniti coram nobis compareat querimonie capituli Inticensis finaliter responsurus, nobis quoque propter huiusmodi citacionem fidem facias per tuas litteras vel per aliorum, quibus fuerit fides coram nobis et per nos certitudinaliter adbibenda. Datum Brixine sabbato proximo $0^{\circ}$ ) ante diem Palmarum anno etc.

10.

Der Dekan Heinrich $\left.{ }^{2}\right)$ und das Kapitel zu Innichen ernennen den Chorherrn Heinrich zu ihrem Proliurator bei der vor dem Bischof Johannes von Brixen oder dessen Stellvertreter stattfindenden Verhandlung gegen den Chorherrn Gerold ( $f .7)$.

[Vor 1321]

a) cod. digno - b) fehlt cod. - c) cod. proxima.

1) Johann Bischof von Brixen 1306-1321.

2) Heinrich Binge de Monte, Dekan 1309-1321 (nach Resch und Sinnacher), er starb 1321 Mărz 7 (lib. obl. Inticen). 
11.

Bischof Johann von Brixen benachrichtigt die Geistlichen des Archidiakonates Pustertal, dass über Hainzlin Sartor aus Anras und Wiclin den Sohn des Jaeklein aus Chroden wegen Blutvergiessens auf dem Friedhof zu Anras die Exkommunikation verhängt werden uird, und beauftragt sie, diese bekannt zu machen ( $f .4)$.

[Vor 1321].

Johannes miseracione divina ecclesie Brixinensis episcopus universis plebsnis, viceplebanis ac aliis ecclesiarnm rectoribus per archidiaconatum vallis Pustrisse constitutis, ad quos presentes pervenerint, salutem in domino. Cam [per] $]^{\mathrm{a}}$ ) Hainzlinam Sartorem de Anras ${ }^{1}$ ) et Wiclinum filium Jaekleini de Chroden sit cimiterium parrochialis ecclesie in Anras propter eorum violenciam sanguinis effusione violatum, quos ob banc cansam, nisi sufficientem de satisfaciendo prestiterint caucionem, per plebanum ipsius ecclesie mandamus, trina monicione premissa, excommunicacionis sentencia innodari. Quam sentenciam, cum per plebanum predictum excommunicati fuerint, execucioni mandetis ipsos excommunicatos denunciando singulis diebus dominicis') et festivis. Datum etc.

12.

Bischof Johann von Brixen beauftragt den Vizepfarrer Gerold an der Laurentiuskirche bei Bruneck, dafür zu sorgen, dass Friedrich von Michaelsburg, der vor Aufhebung seiner Exkommunikation gestorben ist nicht an einem geweihten Ort begraben werde $(f .7)$.

$$
\text { Brixen [ror 1321]. }
$$

Johannes ${ }^{c}$ miseracione divina ecclesie Brixinensis episcopus discreta viro domino Geroldo viceplebano ecclesie sancti Laurencii prope Pranek$\operatorname{kam}^{2}$ ) salutem in domino. Intelleximus, quod dominus Fridericus de castro sancti Michaelis ${ }^{3}$ ) viam universe carnis prochdolor sit ingressus. Cum igitur ex violencia manuum iniectione in se excommunicacionis sentenciam ${ }^{d}$ ) incurrerite), a qua non fait absolutus, mandamus sub virtute sancte obediencie, ut ipsum in aliquo loco consecrato non sepelias nec paciaris ab aliquibus aliis sepeliri. Datum Brixine die quarta etc.

a) Fehlt cod. - b) cod. domicis - c) voraus geht im cod. venerabili in Christo patri, Wiederholung des Eingangs von n. 24. - d) cod. summam - e) cod. incurreit.

1) Anras bei Innichen.

2) S. Lorenzen b. Bruneck.

3) Schloss Michaelsburg Sw. von Bruneck. 
13.

Der Dek(u) M(arquard)1), Hugo von Schneeberg $\left.{ }^{2}\right)$, Heinrich Lucerna ${ }^{3}$ ) und das Kapitel zu Innichen teilen $F$ (riedrich), dem Kapellan von S. Augustin und Generalvikar von Brixen ${ }^{4}$ ) mit, dass Rüdiger, Heinrich, Friedrich und Andreas Pfaffenstoche 5 ), Oheime des Akolythen Nicolaus von Innichen ${ }^{6}$ ) in Laibach 7 ), in Gegenwart seiner Mutter Dyemud, seines Bruders Johannes und seiner Freunde Gerold und Altmann, am Tage des heil. Othnar ihnen die nachfolgend genannten Besitzungen überwiesen haben, um sie dem Nicolaus zu übertragen. Diese sollen teils völliges Eigentum des Nicolaus, teils Eigentum der Kirche zu Innichen sein, doch soll von letzteren Nicolaus gegen jährliche Abgaben die Nutzniessung haben. Als Eigentum der Kirche zu Innichen wurden ïbergeben: 1. von Andreas ein Acker gen. Portpeunt ${ }^{8}$ ), ein Acker mit unliegender Wiese gen. Anger, eine Wiese unter Zachental, 2. von Friedrich ein Acker in dem Zagele, 3. von Heinrich ein Haus nebst Platz, 4. von Dyemud ein Acker ger. Sluzelpeunt, 5. ebenfalls von Andreas ein Haus in der Hüben nebst Platz, dazugehörigem Acker und Gärten. Als freies Besitztum des Nicolaus wurden übergeben: 1. von Rüdiger ein Haus nebst Platz und anliegendem Gebiet, 2. von Gerold ein Haus nebst Platz, anliegender Peunt und zuei Äckern in Pichel, 3. von seinem Bruder Johannes drei Äcker in Innichen, 4. von Altmann ein Haus nebst Platz. Ausserdem bittet das Kapitel, dem Nicolaus die höheren Wiihen zu erteilen. Seript. in choro Inticensi in die predicto VII indictione. Unter dem Siegel des Kapitels (f. $\left.5^{\mathbf{v}}\right)$.

Innichen 1324 November 16.

1) Marquard II. von Tessenberg war 1321-1338 Dekan (vgl. Zahn II, 577, 586, OR. 2582, 2584, u. 8. w. 2627, 2652), im lib. oblat. unter März 12.

9) Hugo von Schneeberg häufig erwähnt (OK. 2588-2600, 2620 u. 8. พ. 2635-38), er war 1338-1341 Dekan, im lib. oblat. unter Mai 3 mit grossen Schenkungen.

3) 1307 als Chorherr von Innichen genannt (Zahn II, 468) 1317-1322 Pfarrer in Toblach, seit 1322 Kustos und Senior ron Innichen, im lib. oblat. unter Oktober 28.

4) Noch 1327 erwähnt (OR. 2600).

5) Andreas de Pfaffenstoche 1332 (OR. 2634) und 1337 (Zahn II, 662) als in Innichen ansässig erwähnt.

b) Wohl später Chorherr in lunichen, als solcher 1344 genannt (OK. 2675).

7) In Erain.

s) Die Ortsbezeichnungen beziehen sich alle auf Innichen, im lib. oblat. verschiedentlich erwähnt. 
14.

Graf Albert von Görz und Tirol bittet Bischof Albent von Brixen, seinerm Notar F(riedrich) ein beneficium ecclesiasticum zu verleihen (f. $\left.2^{\nabla}\right)$.

[Nach 1324].

Reverendo in Christo patri ac domino domino Alberto de Enna venerabili episcopo ecclesie Brixinensis ${ }^{1}$ ) Albertus comes Goricie ac Tyrolis ${ }^{2}$ ) se. promptum et paratum in omni genere obsequii et honoris. Venerandam paternitatem vestram sub plena confidencia seriose petimus ot rogamus,. quatenus $\mathrm{F}$ (ridericum) scolarem ac notarium nostre curie aliquo ecclesiastico, beneficio dignemini graciosius promovere, ut nostrarun instancias precum. in hac parte senciata) esse fructuosas.

15.

Konrad Porger zu Innichen ${ }^{3}$ ) bittet Wolfhard, Propst von Innichen 4 ), ihn gegen einen gewissen Horesnovarius zu schiitzen, der ihn wegen eires ihm von diesem zustehenden Zehnten belästigt und angreift (f. $2 v$.

[Nach 1324].

16.

Graf Albert von Görz und Tirol teilt Bischof Albert von Brixen mit, dass er Jakob ron Innichen, der zur Kirche in Freising gehört, bei sich aufgenommen habe, und bittet, diesem die höheren Weihen zu erteilen $(f .3)$.

Bruch [nach 1324].

De comite ad episcopum.

Reverendo in Christo patri ac domino suo karissimo Alberto venerabili episcopo ecclesie Brixinensis Albertus comes Goricie ac Tirolis affectuosib) boni animi complacendum. Veneranda paternitas vestra noverit per presentes, quod Jacobum de Intica exhibitorem presencium, bone conversacionis iuvenem, flium ecclesie Frisingensis ac de thoro legittimo generatum ad mensam nostre curie collegimus et eidem in universis amminiculis [?] corporis per nos et nostros beredes pro sue vite tempore volumus providere $\left.{ }^{c}\right)$. Unde honorandam paternitatem vestram seriose cum instancia deprecamur, quatenus prefatum Jacobum principaliter propter deum et consequenter ob nostraram precum interventum vestris litteris dimissoriis

-) cod. senciant - b) cod. - c) davor expedire gestr.

1) 1324 Juli \pm bis 1336 November 1 .

2) Albrecht IV. 132t--1374.

8) Wird 132] genannt (OR. 2583). in lib. oblat. unter November 24.

) Wolfhard rorher Kanonikus und Erzdiakon in Freising war 1321-1350 Propst. 
ad maiores ordines suscipiendos favorabiliter dignemini promovere, si vestra benignitas breviter non intendat celebrare. Datam in Prakke ${ }^{1}$ ) tali die etc.

17.

Graf Albert con Görzz ersucht den [Herzog Heinrich von Kärnten-Tirol], die unrechtmässige Erhebung einer Steuer von görzischen Leuten auf dem Ritten durch den Richter in Stein abzustellen ( $f .17 v)$.

[Nach 1324].

Excellentissime domine, Albertus dei gracis [comes Goricie et Tyrolis]ª) cum sui recommendacione devota sincerum animum in omnibus complacendi ${ }^{8}$ ). Ad audienciam nostram ${ }^{b}$ ) pervenit, quod index vester in Stain ${ }^{3}$ ) ab hominibus nostris in Ritina quandam stiuram extorqueat et requirat, que actenus ab ipsis numquam fuerit acceptata sen quomodolibetc) competita. Qnapropter excellenciam vestram rogamus attente precibus affectuosis, quatenus eundem indicem vestrum $\mathrm{ab}$ indebita extorsione huiusmodi cessare et desistere facietis, quia non speramus, quod talem abusum ex novo inchoatum vestris temporibas in hominibus nostris aliqualiter sustinere et pignora ablata propter eandem stiurnm sine difficultate restituere faciatis. Datum.

\section{8.}

Bischof Albert von Brixen bittet das Kapitel zu Innichen, seinen Notav Hartmann zum Chorherrn zu uählen [f. $3^{\vee}$ ].

$$
\text { [1325 März]4). }
$$

Nos Al(bertus) de Enna dei et apostolice sedis gracia episcopns ecclesie Brizinenzis viris honorabilibus et discretis Marquardo decano totique capitulo ecclesie Inticensis salutem in domino salvatore. Cum ex antiqus consuetudine omnes nostri predecessores videlicet episcopi dicte nostre ecclesie Brixinensis suas primarias peticiones pro uno canonics eligendo ad capitulum [ecclesie $]^{2}$ ) Iuticensis ${ }^{d}$ ) semper actenuse) porrigere habuerint ac etiam peticiones haiusmodi sine contradictione aliqua exandiri [debeant] ${ }^{a}$ ), sic et nos, ne talis antiqua et racionabilis consuetudo a dicta nostra ecclesia per nostram neglienciam dilabatur, devocionem vestram sab plena confidencia seriose requirimus et hortamur, quatenus discretum virum Hartmannum nostre curie notariam, exhibitorem presencinm, vestrum ac dicte vestre ecclesie Inticensis eligere velitis ad primarias nostras preces

a) Fehlt cod. - b) cod. restram. - c) cod. quornmlibet - d) cod. Inticine. - e) cod. actenos.

1) Schloss Bruck bei Lienz im Pustertal.

2) Das Schreiben kann wohl nur an Herzog Heinrich ron Kärnten-Tirol (1310--1335) gerichtet sein, als Landesfürsten des Richters von Stein.

9) Stein auf dem Ritten bei Bozen.

4) Die Datierung ergibt sich aus der nächsten Urkunde. 
concanonicum et confratrem, per quod nos sinea) dubio ad vestram promocionem et sepedicte vestre ecclesie commodum et ntilitatem habebitis ferventius inclinatos.

19.

Der Dekan Marquard und das Kapitel zu Innichen teilen dem Bischof Albert con Brixen mit, dass die Wahl des Notars Hartmann zum Chorherrn vorgenommen werden wird, und dass dazu die abwesenden Mitglieder aufyefordert werden sollen. Scriptum in choro Inticensi $a$. $d$. $M^{\circ} C C C^{\circ} X X I I I I^{\circ}$ proxima die ante festum annunciacionis b. Marie virginis feria quinta marcio exeunte ( $\left.f .3^{\nabla}\right)$.

Innichen 1325 März 24.

20.

Der Dekan Marquard und das Kapitel zu Innichen fordern die aussuärtigen Mitglieder auf, zu einer Kapitelsitzung nach Ihnichen zu kommen oder einem anderen Chorherrn ihre Stimme zu übertragen (f. 4).

Innichen [1325] Juli 8.

Marquardus permissione divina decanus totumque capitulum ecclesie Inticensis dilectis sibi in Christo confratribus et dominis ${ }^{b}$ ) Ottoni plebano in Matray ${ }^{1}$ ), Sybottoni viceplebano in Bens ${ }^{2}$ ), Alberto plebano in sancto Laurencio ${ }^{3}$ ), Ottoni cappellano domini Goricie, Engelmanno de Cluna4), canonicis einsdem ecclesie Inticensis, salutem sinceram in domino karitatem. Noverit vestra dilectio per presentes, quod reverendus in Christo pater et dominus dominus Albertus de Enna renerabilis episcopus ecclesie Brixinensis suas primarias peticiones porrexit attencius ${ }^{\mathfrak{c}}$ ) exortando, ut discretum virum dominum Hartmannum sue curie notarium ad primarias suas preces debeamus eligere in nostrum ac dicte nostre ecclesie Inticensis concanonicum et confratrem. Unde karitatem acd devocionem restram exhortamur firmiter et monemus vobisque nichilominus iniungimas et man. damus, ut feria quarta ante festum sancte Margarete presencialiter ${ }^{\theta}$ ) vel per certos et legitimos procuratores in choro Inticensi in capitulo velitis omni dilacione postposita comparere ibidem nobiscum deliberaturif ), quod super electione premissa ac super aliis legitimis negociis dicte nostre ecclesie imminentibus sit potissimum et apcius faciendum. vel si placuerit

a) cor. super - b) davor meis gestr. - c) cod. actancius - d) davor vestran gestr. - ") cod. - f) corr. aus deliberata.

1) Matrei im Wiptal, Otto erscheint 1319, 1327 und 133) (Sinn. 4, 479: OR. 2603, 2624), seine Eltern stehen im lib. oblat. unter Mai 5.

*) Pens im Sarntal b. Bozen.

3) Albert iunior 1317 genannt.

4) $1330^{\circ}$ erwähnt. 
in aliquem vél in aliquos ex nobis, qui presentes sumas, super premissis vestras voces sab certis ac sigillatis vestris litteris transferatis. Scriptum et datum in choro Inticensi feria secunda ante festum beate Margarete etc.

21:

Sybotho, Vizepleban in Pens, überträgt seine Stimme für die Kapitetsitzung in Innichen auf Otto, Pfarrer in Matrei (f. 4).

$$
\text { [1325 Juli]. }
$$

Ego Sybotto canonicus ecclesie Inticensis viceplebanas in Bens publice profiteor in scriptis, quod vocem meam, quam habeo in electione canonicorum predicte ecclesie Inticensis, que nanc feri debet, in discretum virum dominum Ottonem plebanum in Matray concanonicam meum pure transfero, dans sibi plenam potestatem faciendi universa et singala, eciamsi speciale mandatum exigant, que ego in dicta electione facerem, si presens essem propria in persona. Do sibi eciam potestatem, si personaliter Inticain venire non poterit, ut ipsam meam vocem in aliuma) transferre valeat et alium quoad predictam electionem procuratorem substituere, quem ad hoc sibi duxerit eligendum, et promitto me ratum et firmum habere, quidquid mihi per prefatum dominum Ottonem factum et ordinatum fuerit. Scriptum et datum.

22.

Otto, Chorherr zu Innichen und Pfarrer in Matvei, überträgt, da er verhindert ist, selbst nach Innichen zu kommen, seine Stimme und die des Sybotho, Vizeplebans in Pens, für die Wahl eines Chorherrn auf den Chorherrn Heinrich Lucerna $\left(f .6^{\vee}\right)$.

[1325 Juli].

23.

Graf Albert von Görz bestätigt seinem Kellermeister in Virgen den Empfang genannter. Leistungen (f. 3).

Schloss Virgen 132.j um September 11.

Racionem ponere.

Sub indictione octava1) nos Albertus comes Goricie ac Tyrolis recognoscimus per presentes, quod Perchtoldus celerarius noster in Virga ${ }^{2}$ ) a proxima die ante festum sancti Augustini per $X V$ dies continue numerandos nobis in Virga existentibas infrascripta ministravitb): primo triticic)

a) Verbessert aus aliam - b) cod. ministrantur - c) cod. triticii.

1) Hieraus ergibt sich das Jahr 1325.

z) Virgen in Tirol bei Windisch-Matrei. 
modios III cal(veias) $)^{1}$ ) IIII, siliginis totidem. arene modios V, farine cal(veias) VI, sagiminis scutellas Il pro tribus libris computataga). Item offertorio solidos XVI, item caseos LX. Datum in castro Virgen.

24.

Das Kapitel zu Innichen bittet Johannes von Bozen, Chorherrn zu Innichen und Generalrikar von Brixen, dem Chorherrn Heinrich die Subdiaconatsweihen zu erteilen ( $f .7)$.

[Um 1.326].

Venerabili in Christo patri ac domino magistro Johanni de Bozano canonico ecclesie Inticenzis ${ }^{2}$ ) necnon Brixinensis in spiritualibas vicario generali, Mar(quardus) permissione divina decanus ${ }^{3}$ ) totnmque capitulam dicte $^{b}$ ) ecelesie Inticensis oraciones in domino cum obsequio semper prompto. Cum ad presens in prefata nostra ecclesia Inticensi subdiaconis careamus, venerande paternitati vestre cum instancia supplicamus, quatenus Hainricum concanonicum et confratrem nostram, exbibitorem presencium, acolitam bone conversationis iuvenem ac de thoro legittimo generatum cam restris dimissoriis ad subdiaconatus ordinem suscipiendum nostri amoris intuitu favorabiliter dignemini promovere. Datum etc.

25.

Col von Flachsberg, Burggraf zu Lienz, bittet seinen Schwager Hermann von Schwangau, Burggrafen zu Haberberg, ihm ein Pferd zur Verfiigung zu stellen, da er mit Graf Albrecht ron Görz nach Österreich ziehen will $(f .9)$.

[Uin 13\%6].

Dilectissimo genero suo Hermanno de Swangeu purchgravio in Haberberch et in monte sancti Petri ${ }^{4}$ ) Cholo de Flasperch capitaneus in Lunz ${ }^{5}$ ) inviolate dilectionis affectum cum obsequio semper prompto. Tue îdelitatis sinceritas noverit per presentes, quod nobilis ac magnificus dominus meus dominus Albertus illustris comes Goricie piis suis exhortacionibus mihi institit [et] $]^{c}$ ) adiacet seriose, ut cum decem galeis secum in expedici-

a) cod. computatos - b) übergeschr. - c) fehlt cod.

1) Gewöhnlich galveia, Galvei, Galtel, auch çaluja, der dritte Teil eines Stars (vgl. Du Cange u. Schneller, Die romanischen Volksmundarten in Südtirol I, 226).

2) Wird 13:6 erwähnt.

3) Vgl. S. 403 Anm. 1.

4) Haberberg ein beute verschwundenes Schloss bei Innichen. Von Hermann von Schwangau besitzen wir eine Lirkunde von 13:6, in der er gegen Bischof Konrad ron Freising auf die ihm verliebene Burghut resigniert (Zahn II, 566).

5) Flachsberg in Kårnten. In der eben genannten Urkunde wird Col als Mitbesiegler aufgeführt, sonst noch 1311 (OR. 2022) und 1317 (eb. 2576). 
onem versus Austriam proficiscar. Cuius quibus peticionibus aquievi et omnia mibi ad meam expedicionem necessaria tam in equis quam in armis et aliis quibuscumque ad decem pertinencis galeas procuravia), preter quod equo ambulante mee persone abili adhuc careo, quodb) menm iter pro parte impedit et retardat. Sed quia te ad presens equum ambulantem michi satis validum et utilem habere cognosco, ideirco dilectioni tue sub plena confidencia supplico precibus affectivis, quatenus mibi predictum equum per exhibitorem presencium, sicut de tue karitatis exhibicione utique confido, transmittere non differas quoquo modo sine dubio recognoscentes, quod tue fidelitati non solnm in consimilibus verum eciam maioribus sicut merito teneor complacebo, ipsum tamen equam per tai amoris arbitrinm persolvendo. Datum.

26.

Ulrich von Taufer's ${ }^{1}$ ) verkauft seine in Winnebach (Binnenpach) und Arnbach') gelegenen Besitzungen mit allem Zubehör an Konrad von Aufenstein ${ }^{3}$ ) für 300 Mark und verspricht gleichzeitig nach Landessitte für sich und seine Erben, Konrad und dessen Erben bei allen Schädigungen, die dem Besitze drohen, zu verteidigen und zu schützen. Act. Tervisii) in platea ibidem a. d. Mo CCC XXVIII nono intrante marcio (f.2).

Tretiso 1328 März 9.

27.

Der Dekan Marquard und das Kapitel zu Innichen bitten Bischof Albert von Brixen, dem Ulrich, Pfarrer in Niederdorf ${ }^{5}$ ), Heinrich, Vizepleban in Toblach ${ }^{6}$ ), Seifrid, Vikar in Innichen, und Bertold, Pfarrer in Sillian ${ }^{7}$ ), das Recht zu geben, ihre Pfarrkinder durch geistliche Strafen zur Zahlung des Zehnten zu zwingen (f. 3).

[1328?] August 167).

a) cod. procurandas - b) cod qui.

1) Ulrich III. Graf von Taufers 1312-1337, ein anderer Verkauf durch ihn 1312 (OK. 2023), eine Belehnung 1314 (eb. 2025), vgl. über ihn Gebhardi IlI., 572.

2) Beide im Bezirke Sillian. tinense).

3) Aufenstein bei Matrei. Konrad starb 1339 Norember 18 (Necrol. Wil-

4) Treviso.

5) Auch OR. 2637.

8) Auch OR. 2587 .

7) Diese Pfarren wurden erst 1328 mit dem Stift Innichen vereinigt; die Verhandlungen darüber bei Zahn II 577, 580, 581, 585, 587. Die Namen der Pfarrer werden dabei nicht erwännt. Wahrscheinlich wurde die obige Bitte bald nach der Vereinigang ausgesprochen, daher die Datierung.

Mitteilangen XXXI. 
28.

Der Dekan Marquard1) und das Kapitel zu Innichen bitten den Mropst Wolfhard von Röchling, die. Wahl des Scholaren Komrad, des Sohnes des Walther:), zum Chorherm zu bestätigen. Dat. in choro Inticensi in capitulo proxima feria tercia post festum b. Galli proxime nunc transacto a. d. $M^{\circ} \mathrm{CCC}^{\circ} \mathrm{XXVIIH^{ \circ }}\left(f . \tilde{j}^{\mathrm{r}}\right)$.

Innichen 1328 Ohtober 18.

29.

Der Dekan Marquard und das Kapitel zu Innichen teilen ihrem Propste Wolfhart mit, dass sie, seinem Wunsche entsprechend, den Mathias Horsnovarius zum Chorherrn gewählt haben, ihm aber nach ihrem Brauche zunächst mur die Einkünfle einei halben Praebende gewähren können (f. 3).

Innichen 1328.

De servo ad dominum vicem saam gerens ${ }^{3}$ ).

Reverendo in Christo patri ac domino domino suo karissimo domino Bolfardo venerabili preposito ecclesie Inticensis Mar(quardus) decanus totumque capitulum eiusdem ecclesie rel predicte ecclesies) oraciones in domino continuas ac devotas cum obsequio semper promto. Litteris vestri, reverenter ut lecuit susceptis et plenins intellectis, invenimus in eadem serie vestre paternitatis peticiones porrexisse, ut Mathie Horsnovario pro canonico nostro divine remuneracionis intaitu deberemus prebendam integram asignare. Super quo vobis duximus respondendum, quod predictum Matbyam principaliter propter deum et consequenter ob vestrarum precum reverenciam non sub alia forma nisi secundum antiquam formam et consuetudinem electionis dicte nostre ecclesie actenu $s^{b}$ ) habitam et conservatain elegimus in nostrum concanonicam et confratrem. Qui tamen Matthyas purus laycus existens post electionem tantum ${ }^{c}$ ) in acolitum est ${ }^{\mathrm{d}}$ ) promotus, quem ob eandem causam, cum purus laycus ad spirituale beneficium eligi non poterat, $o b$ vestram reverenciam et honorem iterito elegimus in nostrum concanonicum et cunfratrem, dando sibi dimidie fructus prebende tamquam omnibus aliis nostris fratribus exspectantibus electis ac eciam confirmatis re vera scientes, quod nullus nostrorum confratrum esspectancium sive

a) vel pred. eccl. ist formelhafter Einschub. - b) cou. actenos - ciübergeschrieben - d) davor tantum gestr.

1) Der cod. hat Hainricus, da dieser aber bereits 1321 starb (rgl. S. 40. Anm. 2) und nicht unter Wolfhard sein Amt versah, so ist hier ein Versehen de: Schreibers anzuvehmen.

?) Wird noch 1370 als (horherr genannt.

3) Die Überschrift erscheint in diesem Falle sehr uncrkwürdig. 
sacerdos sive dyaconus vel cuinscumque ordinis ab antiquo plus quam dimidiam prebendam percepit a qque ad integram complectionem et ordinem electorum. Unde vestram dignacio $\mathrm{nem}^{\mathrm{a}}$ ) non multum agravat et conturbet, si antedictus ${ }^{b}$ ) Mathyas adhuc est in percepcione dimidie prebende. Quamc) cicius debitam tempus se obtulit, sua sibi complebitur prebenda tamquam nostro concanonico et confratri. Seriptum in choro Inticensi anno domini $\mathrm{M}^{\circ} \mathrm{CCC}^{\circ} \mathrm{XXVIIl^{ \circ }}$.

30.

Drr Rat und die Bürger von Augsburg beschweren sich bei Albertino, dem Herrn von Verona, über die Gefangennahme eines Augsburger Chorherrn und zweier Bürger durch Otto von Florenz und bitten um ihre Befreiung; sie erklären sich bereit, auch vor Gericht gegen Otto aufzutreten. $\left(f .4^{v}\right)$.

[Nach 1329].

Viro magnifico et potenti domino Alberino civitatis et dyocesis Veronensis domino temporali ${ }^{1}$ ) consules et aniversitas civium in Augusta promtum et sincerum ad queque eius beneplacita animum et affectum. Nobilitatis vestre excellentie duximus conquerendam, quod dum nuper dominas V̂lricus dictus Cropf eanonicus ecclesie Angustane et duo ex nostris concivibus videlicet Hainricus dictus Stolzhirz et Hainricus dictus Rsem recederent de Verona, adhuc eis in districtu Veronensi et sub vestra iurisdictione existentibus quidam mercutor dictus Otto de Florencia cum suis complisibus invasit eosdem et plagis ac valneribas inpositis contra deum et iusticiam hostiliter captivavit, quos adhac in vestro dominiod) taliter detinet captivatos. Unde cum actenuy tam vestri progenitoris felicis recordationis quam eciam vestris temporibus ${ }^{\theta}$ ) clerus, cives et populus civitatis Auguste in restris districtibus et dominio constituti in rebus et personis securiores quam in partibus propriis exstiterint et uberius defensati, nobilitati vestre omni precum instancia qua possumus supplicamus, qua. tenus memoratos canonicum et concives a vinculis haiusmodi, quibas indebite detinentur, ex speciali gracia dignemini et vestre iurisdictionis debito liberare, maxime cum represalie, quibus unus pro altero interdum inclebite pregravatur, a iure sint penitus interdicte. Notificamas insuper vestre nobilitati, quod predictus Otto mercator et sui in hac parte fautores hoc anno quosdam nostros concives in territorio Paduano nitebantur occupare et temeritate propria captivare, qui tamen per iusticie iurisque remedium de suis exstiterunt manibus liberati, quod et per vos feri ${ }^{i}$ ) firma credulitate speramus. Sciat eciam restra dominacio, quod Ottoni predicto et suis consortibus universi et singuli canonici, cleriei et cives Augustani parati

a) cod. vestra digna(io - b) cod. adictus - c) cod. quia - d) cod. domino e) davor temporali gestr. - i) übergescinrieben.

1) Albertino, Herr von Verona seit 1329, er ist der Sohn des Cangranje von Verona (7gl. Egger, Gesch. Tirols I. $358 \mathrm{f}$ )! 
fuerunt et adhuc sunt in foro competenti, quo actor sequi reum tenetur, conductu et securitate sufficienter prestitis et adhuc prestandis si voluerit ${ }^{\mathrm{a}}$ ) iusticie plenitudinem oxhibere. Datum et scriptum etc.

31.

Gottfried, Propst der St. Moritzkirche in Augsburg, wendet sich in derselben Sache (wie $n r .30$ ) an Albertino von Verona ( $f .5)$.

Augsburg [nach 1329] Oktober 9.

Egregio et potenti domino Alberino capitaneo populi civitatis Veronensis Gotefridus permissione divina prepositus ecclesie sancti Mauricii in Augusta quidquid poterit reverencie, servieii et honoris. Divine maiestatis providencia rebas humanis habundanter providere desiderans, vestre legalitatis strenuitatern ex felici stipite, que semper zelum iusticie copiosius observabat, feliciter derivatam actorem iusticie vos constitait et preposuit in tantam, quod a finibus terre landes vestre insticie perferuntur, afflicti contra insticiam obpressi ad v03 confluentes sea refugientes sint misericorditer per vos actenus relevati, quia in robis habundavit iusticia summum bonorum encium in hac vita reddens unicuique, quod sibi competere videbatur. Sed inimicas humani generis dolens hominem adipisci in terris, quod jpse retinere nequirit in celis, vestre dominacionis excellenciam nititur aliqualiter distarbare procurando, quod hiis diebas Otto mercator do Florencia cum suis in hac parte complicibus sea fantoribus dominum Ůlricum dictum Chropf canonicum ecclesie Augustine, Hainricum dictum Stoltzhirz et Hainricum dictum Raemen cives Angustanos in vestra inrisdictionis districta seu territorio contra insticie tramilem detinuit et adhuc detinet vinculis mancipatos, causam pretendens ut dicitur frivolam et inanem, asserens sibi Augastanos fore in quibusdam debitis obligatos, quod tamen falsissimum est et carens penitus veritate. Nam clerus et populns civitatis Augustane in communi vel divisim sufficienti securitate et conductu prestitis coram iudice competenti et in loco, ubi ssseruntur contractus iniri, parati sunt eis ${ }^{\mathrm{c}}$ ) exhibere iusticie complementum. Quapropter vestre dominacionis elemenciam deprecor presentibus humiliter et exoro, quatenus ifsos in brachio extento de iniquorum et rapiencium manibus dignemini liberare, ne fama vestri nominis, que per totam mundum fama peroptima innotescit et tamquam preciosum unguentum redolet, qui propriis meritis hactenus firmissimus perstitistis opera rei publice taliter insidiancinm valeat denigrari, cum iuri fiet iniuria in repressaliis, quibus unus pro alio pregravatur et dura sunt ac notoria canonum et legum statuta, que puniunt eos, per quos elerici temeritate propria captivantur. Valeat eternaliter ${ }^{d}$ ) vestra benevolencia, sub cuius nominis umbra res publica Veronensis feliciter gubernatur. Datum Auguste septimo idus octobris.

a) verbessert aus volueris - b) übergeschrieben - c) cod. eos - d) ron späterer Hand übergeschrieben. 
32.

Notariatsinstrument: a. d. $\mathrm{M}^{\circ} \mathrm{CCC}^{\circ} X X X \mathrm{I}^{\circ}$ ind. $X V^{\mathrm{a}}$, die $I X^{\circ}$ exeunte madio verkauft Antonius, der Sohn Heinrichs, an Konrad, den Sohn des Nikolaus, einen Acker in pertinenciis s. Rofelli am Orte Rivus der 10 tornaturae') gross ist, zum Preise von 10 librae Bononienses für jede tornatura, zahlbar innerhalb von 14 Tagen. In dieser Zeit soll Antonius dafür Sorge tragen. dass seine Frau Berta und sein Schwiegervater Jakob auf alle Rechte, die sie an dem Acker halen, rerzichten. Konrad leistet eine Anzahlung von 20 librae Bononienses. Fïr Nichterfïllung der Bedingungen ist ausser dem Ersatz des entstandenen Schadens eine Busse von 100 librae Bononienses zu zahlen. Act. Bononie in domo Antonii (f. 19v).

Bologna 1332 Mai 23.

33.

F. Scholar in Padua bittet den Dekan Marquard von Innichen um sein Wohlwollen ( $f .14 \nabla)$.

$[1321-1336]$.

Reverendo in Christo patri ac domino suo domino M(arquardo) venerabili decano ecclesie Inticensis F. scolaris Padue, litterarum illuminari cupiens documentis, se ipsum promtum et paratum ad omnia geners mandatorum. Sicut unicornus de venatorum insidiis per pure virginis ymaginem confidit securius defendi penitus ac tueri, ita reverende pater de auxilio vestro pariter et favore spero uberius et salubrius promoveri ${ }^{2}$ ). Quocirca prudentie paternitatis vestre, de qua gero fiduciam pleniorem, supplico pure propter deum, quatenus me graciosis vestris et jnmensis circumspectionibus in vestre karitatis gremio habere dignemini commendatum mei memoriam in bono facientes, dum execucionis possibilitas vos inveniat aptiorem. Scientes, quod scienciarum facultatibus propono studiosius insudare maxime, ut precipue vobis et communiter $(?)^{8}$ ) omnibus aliis dominis meis raleam placidis obsequiis ancillari.

34.

Eine gewisse Katharina und ihre Schwester Adelheid einerseits und Otto de Endriano und seine Tochter Adelheid, die von Herzog Heinrich von Böhmen ${ }^{3}$ ) als Vormünder der Kinder des verstorbenen Sweiklinus gen. Hulber de Nalles, des Bruders der obengenannten Katharina eingesetzt

a) cod. contra.

1) Ein in Bologna gebräuchliches Ackermass vgl. darüber Du Cange.

2) Über die Legende der Flucht des Einhorns in den Schoss der Jungfrau vgl. C. Cohn, Zur liter. Geschichte des Einhorns (Progr. Berlin 1887), II, 16 ff.

s) Johann Heinrich, Graf ron Tirol 1335-1341; die Orte sind Andrian und $\mathrm{Nals}$ bei Meran. 
sind, andererseits erklären, dass sie für ihre Streitigkeiten über den Nachlass des Heinrich gen. Hulber de Nalles und seines Sohnes Sweiklinus einen gewissen Bertold als Schiedsrichter und den Georius von Angerheim als Oberschiedsrichter gewählt haben. Sie verpflichten sich bei einer Strafe von 50 Mark Veroneser Denare, wie sie in Meran gebraucht werden, sich dem Schiedsspruch zu fügen. Nach geurissenhafter Prüfung der Ansprïche seien die Schiedsrichter zu folgender Entscheidung gekommen: Katharina und Adelheid sollen drei Häuser, einen Acker mit angrenzendem Gebiet und vier Weingärten erralten, die übrigen Besitzungen des. Heinich und Sweiklinus sollen an die Kinder des Letzteren fallen. Die Vormünder der Kinder seien rerpflichtet, der Katharina und Adelheid sümtliche Urkunden über den diesen zugefallenen Besitz zu übergeben. Im Falle des Todes der einen Partei entscheide ïber die Besitzungen das. Landesrecht. Wolle jedoch eine der Parteien die ihr zugefallenen Gitte. ganz oder teilweise verkaufen, so sei sie verpflichtet, die andere Partei einen Monat vor dem Verkauf hiervon zu benachrichtigen und ih. unter Erlass einer Mark Veroneser Denare von der Kaufsumme das Vorkaufsrecht zu lassen. Jede Streitigkeit habe bei der obengenannten Strafe nunmeh. zwischen den Parteien aufzuhören, über den Vertrag sei jeder. Partei eine. Urkunde auszufertigen (f. 15).

$[1335-1341]$.

35.

Ein Fürst kü̈digt seiner Schwester Ofmia [Gräfin von Görz] die Sendung eines vertrauenswoürdigen Boten an $\left(f .17^{v}\right)$.

Inclite principi sorori sue karissime ofmie etc. fraterne dilectionis constanciam cam salute. Sicut nobis vestra littera suplicastis, quodi robis nuncium transmittere dignaremur, scitisa) indubitanter, quod in brevi robis nostrum nuncium ydoneum et expertum transmittimus, per quem nobis vestros defectus et secreta cordis vestri commendare debeatis et nos omnia et singula, que nobis intimaveritis, pro vestra voluntate indubitanter studebimus adimplere. Preterea scientes, quod nostram infirmitatem bene recuperarimus nostri ex gracia salvatoris $\left.{ }^{b}\right)$.

36.

Friedrich Scholar in Wien, teilt seinem Vater Konrad von Innichen ${ }^{1)}$ mit, dass er selbst gesund sei und bittet un Nachricht über das Befinden seiner Eltern. Dat. in Biena in domo Petri (f. $\left.2^{r}\right)$.

a) cod. scientes - b) folgen Federprobeu.

Wien.

1) Wird 1318 als Grundbesitzer in Innichen erwähnt (Z2Ln III, 12 ). 
37.

Ein Scholar bittet seinen Vater dringend, ihm Geld zu senden, da er trotz äusserster Sparsamkeit das mitgenommene ausgegeben habe. Andernfalls sei er gezwungen, in Kürze nach Hause zurïckzukshren und sein Studium aufzugeben. Script. et dat. ut predictum est $\left.{ }^{\mathrm{I}}\right)\left(f .2^{\mathrm{v}}\right)$.

38.

1. Scholar in Pudun teilt seinem Vater Konrad von Innichen mit, dass er zu seinem Studium notwendig zuei Bïcher brauche und bittet, illm dazu sofort durch einen sicheren Boten eine halbe marca Aquilegensium zu senden, dumit er in seinem Studium nicht gehindert werde. Script et dat. anno etc. exeunte mense $\left(f .2^{\nabla}\right)$.

39.

Nikolaus, Student in Padua, bittet seinen Vater Walter, Richter in Welsberg, dafïr zu sorgen, dass er die Einkünfte von seiner Kapelle rechtzeitig erhalte $\left.{ }^{2}\right)(f .14 \nabla)$.

Patri suo precordialiter diligendo Waltero iudici in Welsperch Nic(olaus) studens Padue suas oraciones in domino devotas. De tua sanitate necnon domine et matris mee, fratrum meorum alioramque nostrorum propinquorum intellecta sum ut plurimum consolatus. Et licet corporis oculis vos videre nequeam, attamen mentetenus[?] ac litteratorie vestram affecto presenciam visitare, cupiens vos scire ${ }^{2}$ ), quod ex gracia omnipotentis dei corpore sanus existo et cuncta mihi prospere succedunt, quod de vestra dilectione mens animus andire cottidie concupiscit. Insuper, pater amande, te scire desidero per presentes, quod de peccunia nuper mihi transmissa persolutis debitis prius contractis sustentacionem habeo usque ad mensem Iulii proximum exclusive. Tunc vero tempus instabit, quod omnes studentes societatem contrahunt, hospicia conveniunt ${ }^{b}$ ), que lignis, fromento necnon aliis necessariis more solito muniuntur et est procul dubio et bona provisio, cum tunc temporis victualia reperiantur de precio leviori et quod melins est prevenire quam preveniri. Unde patrum dilectione studeas de proventibus mee capelle taliter isto medio providere, quod tempore prefixo maiorem partem peccunie adipiscar, ut cum aliis faciam ea que videantur ad meam utilitatem et commodum redundare, ne me contingat in posterum

a) cod. scira - b) davor contrahere gestr.

1) Wahrscheinlich echloss sich dieser Brief dem vorhergetenden unmittelbar an.

2) Dies Schreiben ist nieht unwichtig zur Geschichte des nittelalterlichen Studententums. 
pro rebus necessariis sumptus facere ampliores et forte tunc cum istis paucis expensis de mea prebenda provenientibus minus sufficienter transire possem et studium postponere iam feliciter inchoatum.

40.

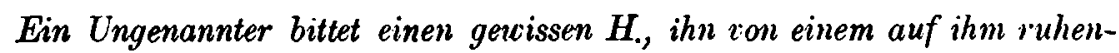
den Verdacht zu reinigen ( $f .1 \tau^{\mathrm{r}}$ ).

Viro discreto et amico speciali $H$. etc. quidquid poterit servicii et honoris amicicie vestre, de qua gero fiduciam pleniorem, notum facio per presentes, quod in turbulacionibus multis positus vestre pietatis auxilium requiro, quia timeo, quod dominus episcopus talis loci etc. mihi iniuriam facere velit propter quosdam detractatores, qui veneno invidie me intoxicare nituntur ${ }^{8}$ ), quia littera domine mee non fuit recepta nec mihi proficua ulla parte. Quare vestram dilectionem, in qua spes mes consistit, bumiliter deprecor et exoro, quatenus mihi de duabus litteris provideatis ad dominum episcopum et ad dominum Jacobum talem etc. ut cognoscant meam innocencium et ad suam graciam et protectionem me recipere dignentur. $I^{b}$ ) protectionem domine mee cum rebus et persona me committo.

\section{1.}

Der Magister Rudolf bittet einen gewissen Petrus, seine Praebende bis zur vollen Zahlung in Sequester zu halten ( $f$. 8).

Domine Petre promissa fideli salutacione. Ego magister Rud(olfas) significo vobis, quod Fr. de Pủhel adhuc non misit mibi XXVIII libras et caseos meliores de prebenda, cum tamen tercia die post Galli mittere finaliter promisisset. Unde supplico, quantum possum, at prebendam meam totam vos et dominus decanus usque ad solucionem habere dignemini in sequestro. Scitis enim, quod de voluntate ipsius Fr. hoc iden nobis firmiter promisistis facientes pro me in hac parte sicut de vobis confirlo, scientes pro certo, quod nunquam cessabo, donec ex mea solicitudine promocionem ${ }^{c}$ ) habebitis, concedente domino vobis graciam sicut vos diligo procuretis, quod ante festum omnium sanctorum caseos cum denariis transmittantur.

\section{Regeln für Notare.}

I.

Qui dictare putas in prima parte salutas, Altera blanditur, per trinam res aperitur,

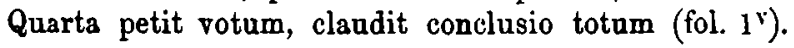

a) cod. mittuntur - b) - davor insuper gestr. - c) cod. permocionem. 
II.

Si bene dictabis, tu quatuor ista notabisa).

Non discordabis partes nec continuabis, Et si dictsbis ${ }^{b}$ ) nec materiam variabis (fol. 17 ).

III.

Nota, quod instrumentum vendicionis sex continet capitula, sunt: contrahentes, rem venditam, precium, possessionis tradicionem, permissionem de legittima defensione, penam cum suis coherentiisc). Incipit capitulam primum mobilium et immobilium rerum diversis titulis et causis, continens donaciones instramentoram, arrarum (fol. 19).

Folgt Urkunde nr. 32, darauf:

Intelligas ponendum esse instrumento, si expressim inter partes agetur ac venditor de fideiussore prestando notatur ${ }^{d}$ ).

(N. S.) Quid est donacio? quedam mea libertas, que nallo tempore urgente aufertur.

IVe).

Ac eciam cum consensu, manu et favore uxoris mee $\mathbf{K}$. et omnium heredum meorum utriusque sexus domino $\mathrm{Chanrado} . . . f)$ in ac suis heredibusf) $\left(\right.$ fol. $\left.1^{\mathrm{v}}\right)$.

\section{Über die comparacio.}

Incipit tractatus comparacionum brevis et atilis compilatus; ad atilitatem parvornm volencium plana via ad grammatice procedere fundamentum iuxta modum doctrinalis, in quantam valeo, scribere cogitavi. Ad habendam igitur noticiam comparacionum primo videndum est, quid sit comparacio et ande dicatur et quot sint gradus comparacionis et quibus modis fiat comparacio et de comparacione regulari et irregulari et sic de singulis breviter est dicendum. Quid est comparacio? B).

\section{Regel für das Aderlassen.}

Adb) sangainem minuendum eaute inspiciendo: luna prima mane, II medio | die, III similiter, IIII mane, V similiter, VI noli uti, VII tota

a) = carebis - b) Et si dict. wohl yerderbt, da nur 3 Punkte genannt sind - c) cod. coberentiis - d) cod. notetur - e) Quer am Rande der Seite, darunter sechs Entwürfe zu Notariatssigneten, ziemlich ungeschickt gezeichnet. - t) abgerissen. - e) fol. 18v, hier abgebrochen, wahrscheinlich sind die folgenden Seiten für die Fortretzung frei gelassen - b) fol. 1 am Rande Lana. 
die, VUI | medio die, VIII noli nti, X tota die, XI sero ${ }^{8}$ ), XII ad febres, XIII to|ta die, XIIII similiter, XV mane, XVI similiter, XVII noli uti, XVIII mane | XIX noli nti, XX sero ${ }^{a}$ ), XXI noli uti, XXII tota die, XXUI similiter, ! XXIII, mane, XXV sero?), XXVI tota die, XXVII tota die, XXVIII | similiter, XXIX mane, XXX noli uti.

Mittelhochdeutsche Verse.

Owe klagent ir raine christenbait

Unsers hertze grosse lait,

Wan uns umberangen bat

Der valsche Juden rat

an dieser jamerlichen stat.

Owe wie jamerlichen ${ }^{b}$ ) es stat,

Da die hert an hert ergat,

Das ist wol an uns schowen

An uns ellenden driu frowen (fol. 13).

$$
\text { Geistliche Verse }{ }^{1} \text { ). }
$$

I.

Salve virgo regia, flos virginum, celi luminaria, |

Regis regum regia mater et filia. Mediatris dei

Et hominum miseroram tympatustria | vena venie fons misericordie.

Tenens regis glorie privileia, | stella lax egreia,|

Speculum mundicie, | plena gracia nos irradia,

Roga dominum pro nobis, pia | tutrix crimi-

num, dele vicia, | cum Christo nos socia. | Tenor.

\section{II.}

De sancto spiritu.

Veni sancte spiritus. (Die bekannte Pfingstsequenz, s. Chevalier, Repertorium hymnologicnm nr. 21242.)

III'2).

Stela maris diceris fixa super ethera lucens, excelsior

Sideris lacens super omnia opem ferre propera eidem ... bus

Miseris sceleris, nos a morte libera.

a) cod. sere - b) cod. jamerchlichen.

1) fol. 13v, sämtlich mit Neumen.

2) fol. 1, wohl stark verderbt. 
Rätsel.

I.

Mater mea domnm, tunicam tibi suma,

Patrem progenies occisit matris in alvo ${ }^{1}$ ).

II.

Est quoddam esse, quod nullus vellet habere, Et si contigerit, perdere noluerit ${ }^{2}$ ).

III.

In densis silvis venor cam quinque catellis, Quod capio, perdo; quod fugit, boc babeo ${ }^{3}$ ).

IV.

Assumus hic omnes, nullus nostrum tamen hic est, Currit et incedit paries, si fronte carebit.

V.

Floribus et lignis vidi mirabile factum, Quod ligno carnit et sine flore fuit").

VI.

Al. pi. pen. ca. bas. tot habet nas, in quod habet gras, Sep. tibi an. tibi sep. can. tibi can. caval, tibique [?] caval babeo.

\section{Chronologische Regeló).}

Notandum quod duplex est ciclus: unus solaris, alius lunaris. Solaris est ille, qui complet cursum suum in XXVIII annis, lunaris est ille, qui complet cursum suum in decem et novem annis. Quilibet illorum ciclorum habet cognosci duobus modis querendo et locando. Primo sciendum est, quod inquirendo cyclum lunarem primo inchoandam est a firmicri [?] articulo pollicis numerando: unus - II - ete. usque ad XIX et

1) fol. 1v, z. B. orum, semen etc.

2) z. B. vita, senectus.

s) Läuse. Dieses Rätsel kommt schon bei den Griechen vor. Herodot berichtet, dass es Fischerknaben dem Homer aufgegeben haben (vgl. Friedrich, Geschichte des Rätsels S. 181). Die latein. Fassung mit den Schluss, quod non capio mihi servo ebd. not. 2 u. 3 und Heidfeld, Sphinx. Philosophica, 2a recensio Herborn 1601 S. 101.

4) Der Traum. Die anderen Rätocl slnd mir unlösbar geblieben.

5) fol. 13, vielfach stark gekürzt, einzelne Lesungen unsicher Text unklar. 
XIX incluso, spacio solum intra manum numeratim procurando(?). In firmiori vero articulo articularis digiti debet locari(?) autem secundum hos versus sequentes: Trinus, unden, nod, octo, sed, quinque, tred, ambo, cecem, dot, septem, quin, quartus, iota ${ }^{a}$ ), sep, novem ${ }^{b}$ ), vi, quartc).

Incipiendo in secundo membro articularis digiti interius et exterins frmiori parte pollicis obmissa ad eiusdem digiti articulum, tota manu transcursa diligencius redeundo, hoc facto cyclus queratur, in quo littere dominicales currunt secundum hune versum: Filins esto dei, celum bonus accipe grates.

Prima designaciod ${ }^{d}$ huius versus est: filins; invenitur in ultimo membro exteriori ipsius indicis et secunda designatiod) est: esto, in proximo articulo hic inncto hoc solo versu; tota manu transcursa excluso pollice usque ad primum membrum articularis digiti intraneum. Super duas istius versus designationes a bisexti designato, in quolibet articularis digiti articulo collocando predicte autem littere dominicales invente, hsbetur breviter per hunc versam: fructus alit canos et callica bellica danus.

a) davor im cod. noch dud - b) übergeschrieben - c) über den Zahlworten stehen im cod. noch die dazu gehörigen Ziffern - d) cod. $d^{\circ}-e^{e}$ cod. $d^{8}$. 